\title{
Outcomes of tranexamic acid administration in military trauma patients with intracranial hemorrhage: a cohort study
}

Patrick F. Walker ${ }^{1 *}$ D, Joseph D. Bozzay ${ }^{1}$, Luke R. Johnston ${ }^{1}$, Eric A. Elster ${ }^{1}$, Carlos J. Rodriguez ${ }^{2}$ and Matthew J. Bradley ${ }^{1}$

\begin{abstract}
Background: Tranexamic acid (TXA) may be a useful adjunct for military patients with severe traumatic brain injury (TBI). These patients are often treated in austere settings without immediate access to neurosurgical intervention. The purpose of this study was to evaluate any association between TXA use and progression of intracranial hemorrhage (ICH), neurologic outcomes, and venous thromboembolism (VTE) in TBI.

Methods: This was a retrospective cohort study of military casualties from October 2010 to December 2015 who were transferred to a military treatment facility (MTF) in the United States. Data collected included: demographics, types of injuries, initial and interval head computerized tomography (CT) scans, Glasgow Coma Scores (GCS), and six-month Glasgow Outcome Scores (GOS). Results were stratified based on TXA administration, progression of ICH, and VTE.

Results: Of the 687 active duty service members reviewed, 71 patients had ICH (10.3\%). Most casualties were injured in a blast (80.3\%), with 36 patients (50.7\%) sustaining a penetrating TBI. Mean ISS was $28.2 \pm 12.3$. Nine patients (12.7\%) received a massive transfusion within $24 \mathrm{~h}$ of injury, and TXA was administered to 14 (19.7\%) casualties. Patients that received TXA had lower initial reported GCS (9.2 \pm 4.4 vs. $12.5 \pm 3.4, p=0.003)$, similar discharge GCS (13.3 \pm 4.0 vs. $13.8 \pm 3.2, p=0.58)$, and a larger improvement between initial and discharge GCS (3.7 \pm 3.9 vs. $1.3 \pm 3.1, p=0.02)$. However, there was no difference in mortality (7.1\% vs. $7.0 \%, p=1.00)$, progression of $\mathrm{ICH}(45.5 \%$ vs. $14.7 \%, p=0.09)$, frequency of cranial decompression (50.0\% vs. $42.1 \%, p=0.76)$, or mean GOS (3.5 \pm 0.9 vs. $3.8 \pm 1.0, p=0.13)$. Patients administered TXA had a higher rate of VTE (35.7\% vs. 7.0\%, $p=0.01$ ). On multivariate analysis, however, TXA was not independently associated with VTE.

Conclusions: Patients that received TXA were associated with an improvement in GCS but not in progression of ICH or GOS. TXA was not independently associated with VTE, although this may be related to a paucity of patients receiving TXA. Decisions about TXA administration in military casualties with ICH should be considered in the context of the availability of neurosurgical intervention as well as severity of extracranial injuries and need for massive transfusion.
\end{abstract}

Keywords: Tranexamic acid, TXA, Traumatic brain injury, TBI, Military

\footnotetext{
* Correspondence: patrick.f.walker.mil@mail.mil

'Department of Surgery, Uniformed Services University of the Health

Sciences and Walter Reed National Military Medical Center, 8901 Rockville

Pike, Bethesda, MD 20889, USA

Full list of author information is available at the end of the article
}

(c) The Author(s). 2020 Open Access This article is licensed under a Creative Commons Attribution 4.0 International License, which permits use, sharing, adaptation, distribution and reproduction in any medium or format, as long as you give appropriate credit to the original author(s) and the source, provide a link to the Creative Commons licence, and indicate if changes were made. The images or other third party material in this article are included in the article's Creative Commons licence, unless indicated otherwise in a credit line to the material. If material is not included in the article's Creative Commons licence and your intended use is not permitted by statutory regulation or exceeds the permitted use, you will need to obtain permission directly from the copyright holder. To view a copy of this licence, visit http://creativecommons.org/licenses/by/4.0/ The Creative Commons Public Domain Dedication waiver (http://creativecommons.org/publicdomain/zero/1.0/) applies to the data made available in this article, unless otherwise stated in a credit line to the data. 


\section{Background}

Tranexamic acid (TXA) may be a useful medication for severe traumatic brain injury (TBI) in austere settings without immediate access to neurosurgical intervention. This is commonly the case in combat, where TBI is often the result of penetrating injury and frequently requires neurosurgical intervention (Fig. 1) [1, 2]. Patients with TBI that require treatment in military settings, however, are often located in remote environments without immediate access to neurosurgical capability. In these circumstances, medical interventions are relied upon to mitigate causes of secondary brain injury, including hypotension, hypoxia, and hyperthermia. Although mass effect from exacerbation of intracranial hemorrhage $(\mathrm{ICH})$ can also contribute to secondary brain injury, preventing this without surgical decompression can be difficult to accomplish [3].

Tranexamic acid (TXA), a medication that inhibits fibrinolysis by blocking the conversion of plasminogen to plasmin, has been theorized to decrease the progression of $\mathrm{ICH}$ [4]. The CRASH-2 study showed that If given within $3 \mathrm{~h}$ from the time of injury, TXA was associated with a survival advantage in civilian trauma patients with or at risk for significant bleeding [5, 6]. A survival advantage has also been demonstrated with TXA administration in military trauma patients [7]. However, the administration of TXA may be associated with thrombotic complications to include an increase in the incidence of venous thromboembolism (VTE) [8]. Current Department of Defense (DOD) Joint Trauma System

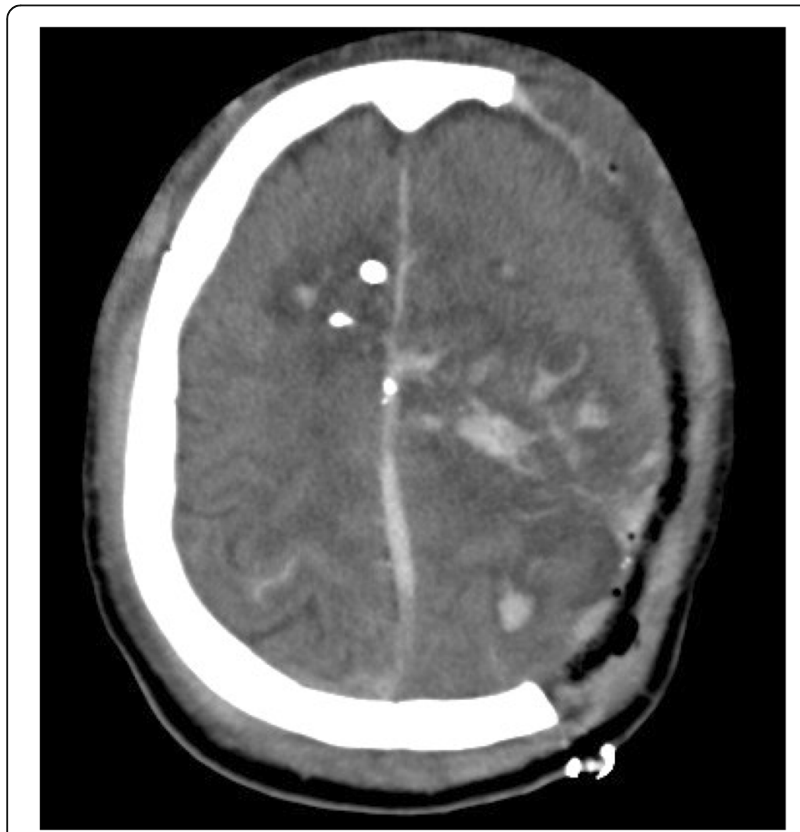

Fig. 1 Computed tomography (CT) scan of patient with transhemispheric gunshot wound and associated intracranial hemorrhage
(JTS) Tactical Combat Casualty Care (TCCC) Guidelines recommend TXA administration if a casualty is expected to need a significant blood transfusion and is able to be started no less than $3 \mathrm{~h}$ after injury, including in cases of hemorrhagic shock, one or more major amputations, penetrating torso trauma, or if severe bleeding is evident [9].

The outcomes of military patients with $\mathrm{ICH}$ who received TXA are not well described. Therefore, the purpose of this study was to evaluate any association between TXA use and progression of $\mathrm{ICH}$ as well as other outcomes including VTE in military patients with $\mathrm{ICH}$. We hypothesized that TXA would not result in any difference in neurologic outcomes but would be associated with an increased incidence of VTE.

\section{Methods}

This is a retrospective evaluation of all military casualties arriving to our military treatment facility (MTF) from October 1, 2010 to December 31, 2015 who were diagnosed with military combat-related $\mathrm{ICH}$. This study was approved by the Walter Reed National Military Medical Center local institutional review board (protocol\# 352329-27). Data was obtained from the Department of Defense Trauma Registry (DoDTR) in addition to the electronic medical record. The DoDTR collects and maintains information regarding the demographics, diagnoses, and interventions of combatant and noncombatant casualties from the point of injury until definitive care in the Continental United States (CONUS) at our Role IV MTF. Patients were excluded if they were not active duty United States service members or if they had incomplete data.

We collected information regarding the types of injuries and injury severity score (ISS), initial and interval head computerized tomography (CT) scans and differences between them, field and discharge Glasgow Coma Scores (GCS), and six-month Glasgow Outcome Scores (GOS) (Table 1). As shown in Table 1, the GOS defines neurologic outcomes 6 months after injury [10]. Patients who underwent craniectomy prior to a follow-up head CT were excluded when determining progression of $\mathrm{ICH}$. Progression of $\mathrm{ICH}$ was determined qualitatively based on radiologist interpretation. Results were stratified based on TXA administration, ICH progression, and VTE occurrence.

Table 1 Glasgow Outcome Scale (GOS)

\begin{tabular}{ll}
\hline GOS 5 & Resumption of normal life, minor deficits possible \\
GOS 4 & Moderate disability without ADL assistance \\
GOS 3 & Severe disability with ADL assistance \\
GOS 2 & Persistent vegetative state \\
GOS 1 & Death \\
\hline
\end{tabular}


For univariate analysis, statistical differences between continuous variables were determined by student's $t$ test for parametrically distributed data and by the Wilcoxon rank sum test for non-parametrically distributed data. Differences in categorical variables were determined by a continuity-adjusted chi-squared test or a Fisher's exact test as appropriate. To evaluate independent clinical risk factors associated with VTE in our cohort, variables found to be statistically significant in univariate analysis were used to create a binary logistic regression model. A $p$-value $<0.05$ was considered statistically significant. Statistical analysis was performed using SAS version 9.4 (SAS Institute Inc., Cary, NC).

\section{Results}

687 active duty service members were treated at our facility during the study period. Of these, 71 patients had ICH (10.3\%). Demographic data is shown in Table 2. $100 \%$ of patients were males. Most casualties were injured in a blast $(80.3 \%)$, with $18.3 \%$ of casualties being injured from a gunshot wound. One patient had $\mathrm{ICH}$ from a closed head injury from a helicopter crash. 36 patients $(50.7 \%)$ sustained a penetrating TBI, with $69.4 \%$ of those blast-related and the remaining $30.6 \%$ from gunshot wounds. Most patients had a mixed $\mathrm{ICH}$ pattern that included: $80.3 \%(n=57)$ with intraparenchymal hemorrhage, $60.6 \% \quad(n=43)$ with subarachnoid hemorrhage, $46.5 \%(n=33)$ with subdural hemorrhage, $25.3 \%(n=18)$ with intraventricular hemorrhage, and $11.3 \%(n=8)$ with epidural hemorrhage. Seven patients $(9.9 \%)$ were reported to have diffuse axonal injury.

Mean ISS was $28.2 \pm 12.3$. Nine patients (12.7\%) received a massive transfusion ( $>10$ units $\mathrm{pRBC}$ ) within $24 \mathrm{~h}$ of injury, and TXA was administered to 14 (19.7\%) casualties. Patients that received TXA were more severely injured $(36.6 \pm 12.5$ vs. $26.2 \pm 11.4, p=0.003)$ (Table 2). They were also more likely to have had an INR $>1.5$ (50\% vs. $12.3 \%, p=0.004)$ and lower extremity amputation $(35.7 \%$ vs. $1.8 \%, p<0.001)$. Four patients that were administered TXA (28.6\%) did not have a chest, abdomen, or extremity abbreviated injury scale score of 3 or higher.

Patients that received TXA had lower initial reported GCS (9.2 \pm 4.4 vs. $12.5 \pm 3.4, p=0.008)$, similar discharge GCS (13.3 \pm 4.0 vs. $13.8 \pm 3.2, p=0.58)$, and a larger improvement between initial and discharge GCS $(3.7 \pm 3.9$ vs. $1.3 \pm 3.1, p=0.02$ ) (Table 3 ). However, there was no difference in mortality $(7.1 \%$ vs. $7.0 \%, p=1.0)$, mean 6 month GOS $(3.5 \pm 0.9$ vs. $3.8 \pm 1.0, p=0.13)$, or need for cranial decompression ( $50.0 \%$ vs. $42.1 \%, p=0.76$ ).

26 patients $(36.7 \%)$ underwent cranial decompression prior to their follow-up CT scan and therefore were

Table 2 Clinical characteristics of patients stratified by tranexamic acid administration. Continuous variables expressed as mean \pm standard deviation

\begin{tabular}{|c|c|c|c|c|}
\hline & Total $(\boldsymbol{n}=71)$ & TXA $(\boldsymbol{n}=14)$ & No TXA $(\boldsymbol{n}=57)$ & $\boldsymbol{P}$-value \\
\hline Age, y & $25.2 \pm 4.9$ & $24.2 \pm 3.1$ & $25.5 \pm 5.3$ & 0.64 \\
\hline ISS & $28.2 \pm 12.3$ & $36.6 \pm 12.5$ & $26.2 \pm 11.4$ & $0.003^{*}$ \\
\hline Penetrating TBI, $n$ & $36(50.7 \%)$ & $6(42.3 \%)$ & $30(52.6 \%)$ & 0.56 \\
\hline Blast injury, $n$ & $57(80.3 \%)$ & $12(85.7 \%)$ & $45(80.0 \%)$ & 0.72 \\
\hline Gunshot wound, $n$ & $13(18.3 \%)$ & $2(14.3 \%)$ & $11(19.3 \%)$ & 0.72 \\
\hline Received massive transfusion within $24 \mathrm{~h}, \mathrm{n}$ & $9(12.7 \%)$ & $4(28.6 \%)$ & $5(8.8 \%)$ & 0.07 \\
\hline Platelets $<100\left(\times 10^{9} / \mathrm{L}\right), \mathrm{n}$ & 7 (9.9\%) & $3(21.4 \%)$ & $4(7.0 \%)$ & 0.13 \\
\hline INR $>1.5, \mathrm{n}$ & $14(19.7 \%)$ & $7(50.0 \%)$ & $7(12.3 \%)$ & $0.004^{*}$ \\
\hline Lower extremity amputation, $\mathrm{n}$ & $6(8.5 \%)$ & $5(35.7 \%)$ & $1(1.8 \%)$ & $<0.001^{*}$ \\
\hline Pelvic fracture, $n$ & $3(4.2 \%)$ & $1(7.1 \%)$ & $2(3.5 \%)$ & 0.5 \\
\hline Chest AIS 3+, n & 17 (23.9\%) & $6(42.3 \%)$ & $11(19.3 \%)$ & 0.2 \\
\hline Abdomen AIS 3+, n & $8(11.3 \%)$ & $3(21.4 \%)$ & $5(8.8 \%)$ & 0.19 \\
\hline Extremity AIS 3+, $n$ & $19(26.8 \%)$ & $8(57.1 \%)$ & $11(19.3 \%)$ & $0.008^{*}$ \\
\hline \multicolumn{5}{|l|}{ Type of ICH } \\
\hline Epidural, $\mathrm{n}$ & $8(11.3 \%)$ & $3(21.4 \%)$ & $5(8.8 \%)$ & 0.19 \\
\hline Subdural, $\mathbf{n}$ & $33(46.5 \%)$ & $6(42.3 \%)$ & $27(47.4 \%)$ & 1.00 \\
\hline Intraparenchymal, n & $57(80.3 \%)$ & $14(100 \%)$ & $43(75.4 \%)$ & 0.06 \\
\hline Subarachnoid, $\mathrm{n}$ & $43(60.6 \%)$ & $8(57.1 \%)$ & $35(61.4 \%)$ & 0.77 \\
\hline Intraventricular, $\mathrm{n}$ & $18(25.3 \%)$ & $6(42.9 \%)$ & $12(21.1 \%)$ & 0.17 \\
\hline Presence of DAI, $n$ & 7 (9.9\%) & $2(14.3 \%)$ & $5(8.8 \%)$ & 0.62 \\
\hline
\end{tabular}


Table 3 Outcomes stratified by tranexamic acid administration

\begin{tabular}{lllll}
\hline & Total $(\boldsymbol{n}=71)$ & TXA $(\boldsymbol{n}=14)$ & No TXA $(\boldsymbol{n}=57)$ & \multicolumn{2}{c}{-value } \\
\hline Underwent cranial decompression, $\mathbf{n}$ & $31(43.7 \%)$ & $7(50.0 \%)$ & $24(42.1 \%)$ & $12.5 \pm 3.4$ \\
Field GCS & $11.8 \pm 3.8$ & $9.2 \pm 4.4$ & $13.8 \pm 3.2$ & $0.008^{*}$ \\
Discharge GCS & $13.7 \pm 3.4$ & $13.3 \pm 4.0$ & $1.3 \pm 3.1$ & 0.58 \\
Change in GCS & $1.8 \pm 3.4$ & $3.7 \pm 3.9$ & $3.8 \pm 1.0$ & $0.02^{*}$ \\
6-month GOS & $3.7 \pm 1.0$ & $3.5 \pm 0.9$ & $4(7.0 \%)$ & 0.13 \\
Mortality, $\mathbf{n}$ & $5(7.0 \%)$ & $1(7.1 \%)$ & 1.0 \\
\hline
\end{tabular}

excluded from determination of $\mathrm{ICH}$ progression to prevent confounding from postoperative changes. Of the 45 patients with an interval CT scan prior to intervention available for analysis, 11 (24.4\%) demonstrated progression of ICH (Table 4). No differences in progression of $\mathrm{ICH}$ were noted between different types of $\mathrm{ICH}$. There was no difference noted in presence of $\mathrm{ICH}$ progression in patients with penetrating TBI, thrombocytopenia, INR $>1.5$, or in those who were administered TXA, although there was a trend towards a higher rate of progression in those patients that received TXA (45.5\% vs. $14.7 \%, p=0.09$ ).

Nine patients in the cohort (12.7\%) were diagnosed with VTE (Table 5). Patients with VTE had a higher mean ISS ( $40.3 \pm 10.7$ vs. $26.4 \pm 11.5, p=0.001)$ as well as more mean ventilator days $(12.1 \pm 5.2$ vs. $5.7 \pm 6.3$, $p=0.004)$ and a higher mean of blood products transfused (44.2 \pm 49.1 units vs. $13.4 \pm 21.8, p=0.008)$. They were also more likely to have had a lower extremity $(66.7 \%$ vs. $24.1 \%, p=0.02)$ or pelvic fracture $(22.2 \%$ vs. $1.6 \%, p=0.04)$ and to have been administered TXA (55.6\% vs. $14.5 \%, p=0.01)$. On multivariate analysis, however, TXA was not independently associated with VTE.

\section{Discussion}

In this study, we found that while there was an increase in GCS improvement with TXA administration in patients with military combat-related intracranial hemorrhage, there was no difference in progression of intracranial hemorrhage, need for cranial decompression, Glasgow Outcome Score, or mortality. Progression of intracranial hemorrhage has been associated with worse neurologic outcomes [11]. As traumatic brain injury is associated with coagulopathy from release of tissue factor [12-14], TXA can potentially decrease progression of intracranial hemorrhage and improve neurologic outcomes by counteracting this coagulopathy. A nested portion of the CRASH-2 study randomized patients with traumatic brain injury to receive TXA or placebo [15]. Although no differences were found regarding progression of ICH between the two groups, TXA use was shown to be safe in TBI patients. A placebocontrolled study from Thailand looking at TXA use in patients with intracranial hemorrhage also did not show a statistically significant change in size of the hemorrhage [4]. Prothrombin complex concentrate has been shown to decrease the growth of intracranial hemorrhage in geriatric trauma patients [16].

The potential use of TXA in for military TBI is of particular interest given the fact that the military is currently moving towards smaller, more remote surgical teams in order to support lower profile military operations [17]. Limited data is currently published about the effects of TXA in military combat-related TBI. Morte and colleagues published a propensity matched analysis looking at NATO patients with any type of head injury who received TXA [18]. They found a decreased mortality rate and improved discharge GCS in patients who received TXA. In comparison, in this study we looked specifically at patients with intracranial hemorrhage on CT scan and had access to six-month neurologic outcomes. While we also found an increase in GCS improvement in patients who received TXA, we did not see a benefit regarding mortality or Glasgow Outcome Score at 6 months. Additional data calls into question the potential benefit of TXA in military patients. In contrast to the MATTERs study, which showed that TXA was associated with a mortality benefit in military trauma patients [6], Howard and colleagues found in a

Table 4 Clinical characteristics stratified by progression of intracranial hemorrhage. ICH, intracranial hemorrhage; TBI, traumatic brain injury; INR, international normalized ratio; TXA, tranexamic acid

\begin{tabular}{lllll}
\hline & Total $(\boldsymbol{n}=45)$ & ICH Progression $(\boldsymbol{n}=11)$ & No ICH Progression $(\boldsymbol{n}=34)$ & $9(26.5 \%)$ \\
\hline Penetrating TBI, $\mathbf{n}$ & $13(28.9 \%)$ & $4(36.3 \%)$ & $2(5.9 \%)$ & 0.70 \\
Platelets $<\mathbf{1 0 0}(\times \mathbf{1 0} \mathbf{9} \mathbf{L}), \mathbf{n}$ & $5(11.1 \%)$ & $3(27.3 \%)$ & $6(17.7 \%)$ & 0.09 \\
INR $>\mathbf{1 . 5}, \mathbf{n}$ & $9(20.0 \%)$ & $3(27.3 \%)$ & $5(14.7 \%)$ & 0.67 \\
TXA administration, $\mathbf{n}$ & $10(22.2 \%)$ & $5(45.5 \%)$ & 0.09 \\
\hline
\end{tabular}


Table 5 Venous thromboembolism risk factors

\begin{tabular}{lllll}
\hline & Total $(\boldsymbol{n}=71)$ & VTE $(\boldsymbol{n}=9)$ & No VTE $(\boldsymbol{n}=62)$ & \multicolumn{1}{c}{$\boldsymbol{P}$-value } \\
\hline ISS & $28.2 \pm 12.3$ & $40.3 \pm 10.7$ & $26.4 \pm 11.5$ & $0.001^{*}$ \\
Lower extremity amputation, $\mathbf{n}$ & $6(8.5 \%)$ & $2(22.2 \%)$ & $4(6.5 \%)$ & $15(24.1 \%)$ \\
Lower extremity fracture, $\mathbf{n}$ & $21(29.6 \%)$ & $6(66.7 \%)$ & $1(1.6 \%)$ & 0.16 \\
Pelvic fracture, $\mathbf{n}$ & $3(4.2 \%)$ & $2(22.2 \%)$ & $3(4.8 \%)$ & $0.02^{*}$ \\
Spinal cord injury, $\mathbf{n}$ & $4(5.6 \%)$ & $1(11.1 \%)$ & $5.7 \pm 6.3$ & 0.43 \\
Ventilator days & $6.5 \pm 6.5$ & $12.1 \pm 5.2$ & $13.4 \pm 21.8$ & $0.004^{*}$ \\
Blood products transfused (units) & $17.3 \pm 28.2$ & $44.2 \pm 49.1$ & $6(9.7 \%)$ & $0.008^{*}$ \\
Received massive transfusion within $\mathbf{2 4} \mathbf{h}, \mathbf{n}$ & $9(12.7 \%)$ & $3(33.3 \%)$ & $1(1.6 \%)$ & 0.08 \\
Administered recombinant Factor VII, $\mathbf{n}$ & $1(1.4 \%)$ & $0(0 \%)$ & $9(14.5 \%)$ & 1.0 \\
Administered TXA, $\mathbf{n}$ & $14(19.7 \%)$ & $5(55.6 \%)$ & $0.01^{*}$ \\
\hline
\end{tabular}

review of 3773 casualties that TXA was not associated with a mortality difference [19].

The potential thromboembolic effects of TXA should be also be considered. In this study, we found that there was a significantly higher rate of TXA administration in patients with VTE. While our multivariate analysis was not significant, this finding is supported by other recent studies. Johnston and colleagues showed that TXA was an independent risk factor for VTE in military trauma patients [8]. A recent study of civilian trauma patients showed that TXA was associated with a more than threefold increase in the odds of VTE [20]. In both these studies, the increased risk of VTE is independent of injury severity, which was not the case in the MATTERs study. One potential reason for this is that the rate of VTE in MATTERs was only $4 \%$, much lower than the 15.6 to $22.6 \%$ incidence reported in other series from the recent military conflicts $[8,21]$.

This study was limited by its retrospective nature and the constraints by which data was collected in the Department of Defense Trauma Registry. Patients were only included if they survived evacuation to the Continental United States, potentially excluding patients who had worse overall outcomes. We also did not have viscoelastic data to get a true sense for the presence of coagulopathy.

\section{Conclusions}

Our study demonstrates that TXA may be associated with short-term neurologic improvement in military patients with intracranial hemorrhage but not in long-term neurologic outcomes or mortality. Additionally, TXA may be associated with an increased risk of VTE in this group. Based on our findings, we recommend that decisions about giving TXA to military trauma patients with suspected TBI should take into consideration extracranial injury severity as well as the proximity to neurosurgical capability for patients suspected to need cranial decompression.

\section{Abbreviations}

TXA: Tranexamic acid; TBI: Traumatic brain injury; ICH: Intracranial hemorrhage; VTE: Venous thromboembolism; MTF: Military treatment facility; $\mathrm{CT}$ : Computerized tomography; GCS: Glasgow coma score; GOS: Glasgow outcome score; ISS: Injury severity score; DOD: Department of Defense; JTS: Joint Trauma System; TCCC: Tactical Combat Casualty Care: DoDTR: Department of Defense Trauma Registry; INR: International normalized ratio; DAI: Diffuse axonal injury

\section{Acknowledgements}

None.

\section{Authors' contributions}

PFW, JDB, and MJB developed the idea for the project; PFW, JDB, and LRJ curated the data; PFW performed statistical analysis; PFW wrote the initial draft of the manuscript; PFW, JDB, LRJ, EAE, CJR, and MJB edited the manuscript and assisted with readying the manuscript for submission. The author(s) read and approved the final manuscript.

\section{Funding}

N/A

Availability of data and materials

Available as requested from the corresponding author (patfwalker@gmail. com).

Ethics approval and consent to participate

Obtained from Walter Reed National Military Center Institutional Review Board.

Consent for publication

N/A

Competing interests

None.

\section{Author details}

${ }^{1}$ Department of Surgery, Uniformed Services University of the Health Sciences and Walter Reed National Military Medical Center, 8901 Rockville Pike, Bethesda, MD 20889, USA. ²Department of Surgery, John Peter Smith Hospital, Ft. Worth, TX, USA.

Received: 10 January 2020 Accepted: 6 May 2020

Published online: 14 May 2020

\section{References}

1. Bell RS, Mossop CM, Dirks MS, Stephens FL, Mulligan L, Ecker R, et al. Early decompressive craniectomy for severe penetrating and closed head injury during wartime. Neurosurg Focus. 2010;28(5):E1.

2. Dubose JJ, Barmparas G, Inaba K, Stein DM, Scalea T, Cancio LC, et al. Isolated severe traumatic brain injuries sustained during combat operations: 
demographics, mortality outcomes, and lessons to be learned from contrasts to civilian counterparts. J Trauma Inj Infect Critical Care. 2011;70(1): $11-8$.

3. Rosenfeld JV, Bell RS, Armonda R. Current concepts in penetrating and blast injury to the central nervous system. World J Surg. 2015;39(6):1352-62.

4. Yutthakasemsunt S, Kittiwatanagul W, Piyavechvirat P, Thinkamrop B, Phuenpathom N, Lumbiganon P. Tranexamic acid for patients with traumatic brain injury: a randomized, double-blinded, placebo-controlled trial. Bmc Emerg Medicine. 2013;13(1):20.

5. collaborators C-2 trial, Shakur H, Roberts I, Bautista R, Caballero J, Coats T, et al. Effects of tranexamic acid on death, vascular occlusive events, and blood transfusion in trauma patients with significant haemorrhage (CRASH2): a randomised, placebo-controlled trial. Lancet. 2010;376(9734):23-32.

6. collaborators C-2, Roberts I, Shakur H, Afolabi A, Brohi K, Coats T, et al. The importance of early treatment with tranexamic acid in bleeding trauma patients: an exploratory analysis of the CRASH-2 randomised controlled trial. Lancet. 2011;377(9771):1096 101-1101.e1-2.

7. Morrison JJ, Dubose JJ, Rasmussen TE, Midwinter MJ. Military Application of Tranexamic Acid in Trauma Emergency Resuscitation (MATTERs) Study. Arch Surg-chicago. 2012;147(2):113-9.

8. Johnston LR, Rodriguez CJ, Elster EA, Bradley MJ. Evaluation of Military Use of Tranexamic Acid and Associated Thromboembolic Events. Jama Surg. 2017;153:169. https://doi.org/10.1001/jamasurg.2017.3821.

9. System D of DJT. Tactical Combat Casualty Care Guidelines. httpwww.usaisr. amedd.army.milpdfsTCCCGuidelinesforMedicalPersonnelFinal.pdf; 2012. p. 114

10. Jennett B, Teasdale G, Braakman R, Minderhoud J, Knill-Jones R. Predicting outcome in individual patients after severe head injury. The Lancet. 1976; 1(7968):1031-4

11. Brott T, Broderick J, Kothari R, Barsan W, Tomsick T, Sauerbeck L, et al. Early hemorrhage growth in patients with intracerebral hemorrhage. Stroke. 1997 28(1):1-5.

12. Halpern CH, Reilly PM, Turtz AR, Stein SC. Traumatic coagulopathy: the effect of brain injury. J Neurotraum. 2008;25(8):997-1001.

13. Zhang J, Jiang R, Liu L, Watkins T, Zhang F, Dong J. Traumatic brain injuryassociated coagulopathy. J Neurotraum. 2012;29(17):2597-605.

14. Harhangi BS, Kompanje EJO, Leebeek FWG, Maas AIR. Coagulation disorders after traumatic brain injury. Acta Neurochir. 2008;150(2):165-75 discussion 175.

15. Study C-2 C Intracranial B. Effect of tranexamic acid in traumatic brain injury: a nested randomised, placebo controlled trial (CRASH-2 Intracranial Bleeding Study). BMJ (Clinical research ed). 2011;343:d3795.

16. Edavettal M, Rogers A, Rogers F, Horst M, Leng W. Prothrombin complex concentrate accelerates international normalized ratio reversal and diminishes the extension of intracranial hemorrhage in geriatric trauma patients. The American surgeon. 2014:80(4):372-6.

17. Edwards MJ, White CE, Remick KN, Edwards KD, Gross KR. Army General Surgery's Crisis of Conscience. J Am Coll Surgeons. 2018;226(6):1190-4.

18. Morte D, Lammers D, Bingham J, Kuckelman J, Eckert M, Martin M. Tranexamic acid (TXA) administration following head trauma in a combat setting: does TXA result in improved neurologic outcomes? I Trauma Acute Care. 2019;87(1):125-9.

19. Howard JT, Stockinger ZT, Cap AP, Bailey JA, Gross KR. Military use of tranexamic acid in combat trauma: Does it matter? J Trauma Acute Care. 2017:83(4):579-88.

20. Myers SP, Kutcher ME, Rosengart MR, Sperry JL, Peitzman AB, Brown JB, et al. Tranexamic acid administration is associated with an increased risk of posttraumatic venous thromboembolism. J Trauma Acute Care. 2019;86(1): 20-7.

21. Hannon M, Tadlock MD, Melcer T, Walker J, Bandle J, Nieses K, et al. Venous thromboembolism after traumatic amputation: an analysis of 366 combat casualties. Am J Surg. 2016;212(2):230-4.

\section{Publisher's Note}

Springer Nature remains neutral with regard to jurisdictional claims in published maps and institutional affiliations.

Ready to submit your research? Choose BMC and benefit from:

- fast, convenient online submission

- thorough peer review by experienced researchers in your field

- rapid publication on acceptance

- support for research data, including large and complex data types

- gold Open Access which fosters wider collaboration and increased citations

- maximum visibility for your research: over $100 \mathrm{M}$ website views per year

At BMC, research is always in progress.

Learn more biomedcentral.com/submissions 